Pacific Journal of Mathematic 


\section{ON BERRY-ESSEEN APPROXIMATION AND \\ A FUNCTIONAL LIL FOR A CLASS OF DEPENDENT RANDOM FIELDS}

\section{Chandrakant M. Deo and H. Ship-Fah Wong}

\section{In this paper we derive a Berry-Esseen type approximation} for a class of dependent random fields and use it to obtain a functional law of the iterated logarithm.

1. Introduction. In recent years there has been considerable interest in multiparameter stochastic collections or the so-called random fields. In this note we deal with stationary, dependent discrete-parameter random field. In [3] a concept of $\phi$-mixing was introduced for such random fields and a functional central limit theorem was proved for them. Here we obtain a Berry-Esseen type approximation for such random fields and use it to prove a functional law of the iterated logarithm.

The set-up and the basic notation is as in [3]. $Z^{q}$ is the set of all $q$-tuples of integers $(q \geqq 1)$. We denote the points in $Z^{q}$ by $\boldsymbol{i}, \boldsymbol{n}$ etc. or sometimes explicitly by $\left(i_{1}, i_{2}, \cdots, i_{q}\right),\left(n_{1}, n_{2}, \cdots, n_{q}\right)$ etc. Let $\left\{\xi_{n}: n \in Z^{q}\right\}$ be a stationary, $\phi$-mixing random field as defined in [3]. We denote the partial sums of this random field by $S_{n}$ or $S_{n_{1}, n_{2}, \cdots, n_{q}}$ i.e.,

$$
S_{n_{1}, n_{2}, \cdots, n_{q}}=\sum_{i_{1}=1}^{n_{1}} \sum_{i_{2}=1}^{n_{2}} \cdots \sum_{i_{q}=1}^{n_{q}} \xi_{i_{1}, i_{2}, \cdots, i_{q}}
$$

where $n_{i} \geqq 1$. If some $n_{i}$ are zero and others $\geqq 1$ then it is convenient to set $S_{n_{1}, n_{2}, \cdots, n_{q}}=0$.

Let $T^{q}=[0,1]^{q}$ be the $q$-fold Cartesian product of the unit interval, and let $D_{q}$ be the Skorohod function space on $T^{q}$. We use the uniform metric $d$ on $D_{q}$ i.e., if $x, y \in D_{q}$ then $d(x, y)=$ $\sup _{t}|x(t)-y(t)|$.

A block $B$ in $T^{q}$ is a product of half-closed intervals i.e., a set of the form $\prod_{i=1}^{q}\left(s_{\imath}, t_{2}\right]$. If $x$ is a function on $T^{q}$ then $x(B)$ denotes increment of $x$ around $B$.

We will assume throughout that:

$$
E\left(\xi_{n}\right)=0 \text { and } E\left|\xi_{n}\right|^{2+\eta}<\infty \text { for some } \eta>0 .
$$

We will also assume the following condition in [3] on the rate of $\rho$-mixing:

$$
\sum_{q=1}^{\infty} r^{q-1} \dot{\rho}^{1 / 2}(r)<\infty
$$


It is proved in [3] that under these conditions: $\lim _{n \rightarrow \infty} n^{-q} \operatorname{Var}\left(S_{n, n, \cdots n}\right)=$ $\sigma^{2}(<\infty)$ where

$$
\sigma^{2}=\sum_{J \in Z^{q}} E\left(\xi_{0} \xi_{j}\right) \cdot \quad\left(\text { Here } \xi_{0}=\xi_{0,0, \cdots, 0}\right) .
$$

To avoid trivial complications we will assume $\sigma^{2}>0$.

We denote by $K_{\sigma}$ the Strassen's set of continuous functions on $T^{q}:$

$$
\begin{gathered}
K_{\sigma}=\left\{x: x\left(t_{1}, t_{2}, \cdots, t_{q}\right)=\int_{0}^{t_{1}} \int_{0}^{t_{2}} \cdots \int_{0}^{t_{q}} y\left(u_{1}, u_{2}, \cdots, u_{q}\right) d u_{1} d u_{2} \cdots d u_{q}\right. \\
\text { where } \left.\int_{0}^{1} \cdots \int_{0}^{1} y^{2}\left(u_{1}, u_{2}, \cdots, u_{q}\right) d u_{1} \cdots d u_{q} \leqq \sigma^{2}\right\} .
\end{gathered}
$$

Theorem 1 below is a Berry-Esseen type theorem dealing with the speed of convergence of (normalized) $S_{n, n, \cdots, n}$ to normality. Theorem 2 is a functional LIL for these partial sums.

Denote by $\left(H_{n}: n \geqq 1\right)$ the sequence of random functions in $D_{q}$ defined by

$$
H_{n}(\boldsymbol{t})=\left(2 n^{q} \log \log n\right)^{-1 / 2} S_{\left[n t_{1}\right]\left[n t_{2}\right], \cdots,\left[n t_{q}\right]}
$$

where $t=\left(t_{1}, t_{2}, \cdots, t_{q}\right) \in T^{q}$ and [·] is the usual greatest-integer function.

\section{Theorems and proofs.}

THEOREM 1. Let $\Phi$ be the standard normal distribution function. Then under (1) and (2) there exists $C>0, \alpha>0$ such that

$$
\sup _{x}\left|P\left\{\sigma^{-1} n^{-q / 2} S_{n, n}, \cdots, n<t\right\}-\Phi(t)\right|<C n^{-\alpha}, \text { for all } n \text {. }
$$

Proof. For simplicity suppose $q=2$.

For given integers $n, a=a(n)$ and $b=b(n)$, let $\mu$ be the largest integer such that $\mu(a+b) \leqq n$. Then subdivide the square $(0, n] \times$ $(0, n]$ into blocks by taking the product of 2 copies of the partition $0<a<a+b<2 a+b<\cdots<\mu(a+b)<n$. If $1 \leqq m \leqq \mu$, denote by $I_{m a}$ the interval $((m-1)(a+b),(m-1)(a+b)+a]$, by $I_{m b}$ the interval $((m-1)(a+b)+a, m(a+b)]$ and $I_{(\mu+1) a}=(\mu(a+b), n]$. Set

$$
\begin{aligned}
& \alpha_{m}(n)=\sum_{j \in I_{m_{1} a \times I_{m_{2} a}} \xi_{j}}(1,1) \leqq m \leqq((\mu+1), \mu+1) \\
& \beta_{m}^{\prime}(n)=\sum_{j \in I_{m_{1} \times I_{m_{2} b}} \xi_{j}}(1,1) \leqq m \leqq(\mu+\mu) \\
& \beta_{m}^{\prime \prime}(n)=\sum_{j \in I_{m_{1} a} \times I_{m_{2} b}} \xi_{j} \quad(1,1) \leqq \boldsymbol{m} \leqq(\mu+1, \mu)
\end{aligned}
$$




$$
\begin{gathered}
\beta_{m}^{\prime \prime \prime}(n)=\sum_{j \in I_{m_{1} b^{\times} I_{m_{2} a}}} \xi_{j} \quad(1,1) \leqq m \leqq(\mu, \mu+1) \\
u_{n}=\sum_{m_{i}=1}^{\prime \prime+1} \alpha_{m}(n) \quad v_{n}^{\prime}=\sum_{m_{i}=1}^{\prime \prime} \beta_{m}^{\prime}(n) \quad v_{n}^{\prime \prime}=\sum_{m} \beta_{m}^{\prime \prime}(n) \quad v_{n}^{\prime \prime \prime}=\sum_{m} \beta_{m}^{\prime \prime \prime}(n) .
\end{gathered}
$$

Then $S_{n, n}=u_{n}+v_{n}^{\prime}+v_{n}^{\prime \prime}+v_{n}^{\prime \prime \prime}$.

Because of condition (2), by Proposition 1.1.20 of [6], we have $E\left(\gamma_{m}^{2}(n)\right)=\#\left(\gamma_{m}\right)\left(\alpha^{2}+\rho_{\#\left(\gamma_{m}\right)}\right)$ where $\gamma_{m}^{2}$ stands for one of the $\alpha_{m}$ or $\beta_{m}^{\prime \prime}, \beta_{m}^{\prime \prime \prime}, \beta_{m}^{\prime \prime \prime}$ and $\sharp\left(\gamma_{m}\right)$ is the "size" of the block $\gamma_{m}$ and $\rho_{\ddagger\left(\gamma_{m}\right)} \rightarrow 0$ if $\#\left(\gamma_{m}\right) \rightarrow \infty$.

Furthermore, as in Theorem 1.1.22 of [6] we get:

(i ) $E v_{n}^{\prime 2} \leqq\left[1+4 \mu^{2} \phi^{1 / 2}(a)\right]\left[\mu^{2} b^{2}\left(\alpha^{2}+\rho_{b}\right)\right]$

(ii) $E v_{n}^{\prime \prime 2} \leqq\left[1+4(\mu+1)^{2} \phi^{1 / 2}(b)\right]\left[\mu^{2} a b\left(\sigma^{2}+\rho_{a b}\right)+\mu b(n-\mu(a+b))\right.$ $\left.\left(\sigma^{2}+\rho_{n-\mu(a+b)}\right)\right]$.

(iii) $E v_{n}^{\prime \prime \prime} \leqq\left[1+4(\mu+1)^{2} \phi^{1 / 2}(b)\right]\left[\mu^{2} a b\left(\alpha^{2}+\rho_{a b}\right)+\mu b(n-\mu(a+b))\right.$ $\left.\left(\sigma^{2}+\rho_{n-\mu(a+b)}\right)\right]$.

For $(1,1) \leqq m \leqq(\mu, \mu)$ define $\alpha_{m}^{\prime}(n)$ to be independent random variables having the same law as $\alpha_{(1,1)}(n)$; then as in Theorem 1.1.22 of [6] we get:

$$
\left|P\left(\frac{u_{n}}{\sigma \sqrt{n^{2}}}<t\right)-P\left(\frac{\sum_{m_{i}=1}^{\prime \prime} \alpha_{m}^{\prime}(n)}{\sigma \sqrt{n^{2}}}<t\right)\right| \leqq(\mu+1)^{2} \phi(b) .
$$

For this computation, it is easy to show that the "end blocks" $\alpha_{m}(n)$ (with $m_{1}$ or $m_{2}$ equal to $\mu+1$ ) become negligible for large $n$.

$$
\begin{gathered}
\left|P\left(\frac{\sum_{m=1}^{\prime \prime} \alpha_{m}^{\prime}(n)}{E^{1 / 2}\left(\alpha_{m}^{\prime}(n)\right)^{2}}<\frac{t \sigma \sqrt{n^{2}}}{E^{1 / 2}\left(\sum \alpha_{m}^{\prime}\right)^{2}}\right)-\Phi\left(\frac{t \sigma \sqrt{n^{2}}}{E^{1 / 2}\left(\sum \alpha_{m}^{\prime}(n)\right)^{2}}\right)\right| \\
\leqq \frac{c_{\delta}(\mu+1)^{2} E\left|\alpha_{(1,1)}^{\prime}\right|^{2+\hat{o}}}{\left[(\mu+1)^{2} E\left(\alpha_{(1,1)}^{2}\right)\right]^{1+\hat{o} / 2}} \leqq A c_{\hat{\delta}}(1+\mu)^{-\hat{\delta}}
\end{gathered}
$$

because by $\left[4\right.$, Lemma 7]. $\quad E\left(\left|\alpha_{(1,1)}\right|^{2+\delta}\right) \leqq A\left(E\left(\alpha_{(1,1)}^{\prime}\right)\right)^{1+\delta / 2}$

$$
\begin{aligned}
& \left|\Phi\left(\frac{\sqrt{n^{2}}}{\sqrt{(\mu+1)^{2} a\left(\sigma^{2}+\rho_{a}\right)}} \cdot t \sigma\right)-\Phi(t)\right| \\
& \leqq \frac{1}{2 \pi e} \max \left(1, \sqrt{\frac{(\mu+1)^{2} a^{2}}{n^{2}}}\left(1+\frac{\rho_{a}}{\sigma^{2}}\right) \mid \sqrt{\frac{n^{2} \sigma^{2}}{(\mu+1)^{2} a^{2}\left(\sigma^{2}+\rho_{a}\right)}}-1\right) \\
& =\psi(n) .
\end{aligned}
$$

From (i)-(vi) and using a similar argument as in Theorem 1.1 .22 of [6], for $\tau>0$

$$
\begin{gathered}
\left|P\left(\frac{S_{n, n}}{\sigma \sqrt{n^{2}}}<t\right)-\Phi(t)\right| \leqq(\mu+1)^{2} \phi(b)+A c_{\delta}(\mu+1)^{-\delta}+\psi(n) \\
+\frac{\tau}{\sigma \sqrt{n^{2}}}+\frac{E v_{n}^{\prime 2}}{\tau^{2} / 9}+\frac{E v_{n}^{\prime \prime 2}}{\tau^{2} / 9}+\frac{E v_{n}^{\prime \prime \prime}}{\tau^{2} / 9} .
\end{gathered}
$$


If we choose $a=\left[n^{\cdot 6}\right] b=\left[n^{\cdot 4}\right] \tau=\left[n^{1-\varepsilon}\right] 0<\varepsilon<1$ then $\mu=O\left(n^{\cdot 4}\right)$ and $n-\mu(a+b)=O\left(n^{\cdot 6}\right)$. Since condition (2) implies that $r^{q} \phi^{1 / 2}(r) \rightarrow 0$; then

$$
\begin{aligned}
&(\mu+1)^{2} \phi(b)=\left((\mu+1)^{4} \phi(b)\right)(\mu+1)^{-2}=O\left(n^{-\cdot 8}\right) . \\
& A c_{\delta}(\mu+1)^{-\delta}=O\left(n^{-\delta(* 4)}\right)=O\left(n^{-\cdot 4 \delta}\right) . \\
& \psi(n)=O\left(\left|\sqrt{\frac{n^{2} \sigma^{2}}{(\mu+1)^{2} a^{2}\left(\sigma^{2}+\rho_{a}\right)}}-1\right|\right)=O\left(\left|\sqrt{\frac{n^{2}}{(\mu+1)^{2} a^{2}}}-1\right|\right) \\
&=O\left(\frac{b}{a}\right)=O\left(n^{-\cdot 2}\right) \\
& \frac{\tau}{\sigma \sqrt{n^{2}}}=O\left(n^{-\varepsilon}\right) .
\end{aligned}
$$$$
\frac{E v_{n}^{\prime 2}}{\tau^{2} / 9} \leqq(\text { constant }) \frac{\mu^{2} b^{2}\left(\sigma^{2}+\rho_{b}\right)}{\tau^{2} / 9} \text { since } \mu^{2} \phi^{1 / 2}(a) \longrightarrow 0 .
$$$$
=O\left(\frac{n^{2-\cdot 4}}{n^{2-2 \varepsilon}}\right)=O\left(n^{2 \varepsilon-\cdot 4}\right) .
$$

$$
\begin{aligned}
\frac{E v_{n}^{\prime 2}}{\tau^{2} / 9} & \leqq \frac{(\text { constant })}{\tau^{2} / 9}\left[\mu^{2} a b\left(\sigma^{2}+\rho_{a b}\right)+\mu b(n-\mu(a+b))\left(\sigma^{2}+\rho_{n-\mu(a+b)}\right)\right] \\
& =O\left(n^{2 \varepsilon-\cdot 2}\right) .
\end{aligned}
$$

Similarly

$$
\frac{E v_{n}^{\prime \prime \prime 2}}{\tau^{2} / 9}=O\left(n^{2 \varepsilon-\cdot 2}\right)
$$

Then

$$
\left|P\left(\frac{S_{n, n}}{\sigma \sqrt{n^{2}}}<t\right)-\Phi(t)\right| \leqq C n^{-\alpha}
$$

if we set: $\varepsilon=\alpha=\frac{1}{15}$ whenever $\delta \geqq \frac{1}{6}$.

$$
\varepsilon=\alpha=.48 \text { whenever } 0<\delta<\frac{1}{6} \text {. }
$$

An analogous proof is valid for the $q>2$, in that case take

$$
\begin{aligned}
& \varepsilon=\alpha=\frac{1}{15} \text { if } \delta \geqq \frac{1}{3 q} \\
& \varepsilon=\alpha=(.2 q \delta) \text { if not . }
\end{aligned}
$$

REMARK. From the proof, it can be seen that a more general theorem can be obtained if we replace $S_{n, n, \cdots, n}$ by $S_{n}$ where $\boldsymbol{n}^{\prime}=$ $\left(n \theta_{1}, n \theta_{2}, \cdots, n \theta_{q}\right) 0<\theta_{i} \leqq 1$. Then we have 


$$
\sup _{n}\left|P\left\{\sigma^{-1} n^{-q / 2}\left(\theta_{1} \cdots \theta_{q}\right)^{-1 / 2} S_{n^{\prime}}<t\right\}-\Phi(t)\right|<C n^{-\alpha} \forall n .
$$

In fact it is in this stronger form that we will use it in the proof of Theorem 2.

THEOREM 2. Let (1) and (2) be satisfied. Then

$$
P\left\{\lim _{n \rightarrow \infty} \sup d\left(H_{n}, K_{\sigma}\right)=0\right\}=1 \text {, }
$$

and

$$
P\left\{\bigcap_{x \in K_{\sigma}}\left[\lim _{n \rightarrow \infty} \inf d\left(H_{n}, x\right)=0\right]\right\}=1
$$

Proof. We will give only a very brief sketch of the proof since the arguments used are fairly standard and can be found e.g., in Chover (1967) and Wichura (1973). Take $q=2$ for simplicity and $\sigma=1$ without loss of generality.

We begin by showing a kind of asymptotic equi-continuity in the following form: Let $B=\Pi_{i}\left(s_{i}, t_{i}\right]$ be a block in $T^{q}$; write $m(B)=\min _{1 \leqq i \leqq q}\left(t_{i}-s_{i}\right)$. Then

LeMma 1. Given $\varepsilon>0, \exists \delta>0$ such that if $B$ is any block with $m(B)<\delta$ then the event $\left\{\left|H_{n}(A)\right|>\varepsilon\right\}$ occurs only finitely often wp.1.

Proof. Standard arguments (using the triangle inequality) such as those appearing on pp.56-59 of Billingsley (1968) show that it suffices to prove the following: Given $\varepsilon>0, \exists \delta>0$ such that

$$
\begin{aligned}
\sum_{n}[ & P\left\{\max _{\substack{1 \leq i \leq n \delta \\
1 \leq j \leq n}}\left|S_{i, j}\right|>\varepsilon \sqrt{\left.2 n^{2} \log \log n\right\}}\right. \\
& +P\left\{\max _{\substack{1 \leq i \leq n \\
1 \leqq j \leqq n \delta}}\left|S_{i, j}\right|>\varepsilon \sqrt{\left.2 n^{2} \log \log n\right\}}\right]<\infty .
\end{aligned}
$$

But this can be proved in a straightforward manner using the maximal inequality developed on pp. 713-714 of [3], Theorem 1 above and the arguments in $\S 3$ of Chover (1967). We omit the details.

Let now $m$ be a positive integer. Consider a partition of the unit square $\left(T^{2}\right)$ into $m \times m$ squares with corners $(i / m, j / m), 0 \leqq i$, $j \leqq m$. We enumerate these squares (blocks) arbitrarily as $B_{i m}$, $1 \leqq i \leqq m^{2}$. Let $\gamma>0$ be a small positive number and denote by $B_{i m}^{*}=B_{i m}^{*}(\gamma)$ the square which is concentric with $B_{i m}$ (and is contained in $\left.B_{i m}\right)$ with each side being equal to $(1-2 \gamma) / m$.

If $x$ is a function on $T^{2}$ we denote by $\pi_{m} x$ the function on $T^{2}$ defined by

$$
\left(\pi_{m} x\right)\left(t_{1}, t_{2}\right)=\int_{0}^{t_{1}} \int_{0}^{t_{2}} \sum_{i=1}^{m_{2}} m^{2} x\left(B_{i m}\right) I_{B_{i m}}\left(u_{1}, u_{2}\right) d u_{1} d u_{2}
$$


where $I_{B}$ stands for the indicator of the block $B$.

Lemmas 2 and 3 below follow easily from the arguments used in proving Corollaries 1 and 2 in Chover (1967). Lemma 4 is immediate from Lemma 1.

Lemma 2. Given $\varepsilon>0, \exists m$ such that

$$
P\left\{d\left(\pi_{m} H_{n}, H_{n}\right)>\varepsilon \text { only finitely often }(\text { in } n)\right\}=1 \text {. }
$$

LEMma 3. Given $\varepsilon>0, \quad \exists c>1$ such that, wp. 1, $\max _{c^{n} \leqq m \leqq c^{n+1}} d\left(H_{m}, H_{\left[c^{n}\right]}>\varepsilon\right.$ for only finitely many $n$.

Lemma 4. Given $\varepsilon>0, \exists \gamma>0$ such that for each $m$ and $i$ $\left(1 \leqq i \leqq m^{2}\right)$,

$$
P\left\{\left|H_{n}\left(B_{i m}\right)-H_{n}\left(B_{i m}^{*}\right)\right|>\varepsilon \text { for only finitely many } n\right\}=1 \text {. }
$$

We now proceed to prove (a) of the theorem. Let $\left\{\theta_{i}: 1 \leqq i \leqq m^{2}\right\}$ be real numbers such that $\sum_{i=1}^{m^{2}} \theta_{i}^{2}=1$. To prove (a) it suffices to show that for each $m$,

$$
P\left\{\sum_{i=1}^{m^{2}} \theta_{i}\left(\pi_{m} H_{n}\right)\left(B_{\imath m}\right)<(1+\varepsilon) \text { for all large } n\right\}=1 .
$$

In view of the preceding lemmas it thus suffices to prove (with $c>1$ sufficiently close to 1 and $\gamma>0$ sufficiently small)

$$
\sum_{n=1}^{\infty} P\left\{m \sum_{i=1}^{m^{2}} \theta_{i} H_{\left[c^{n}\right]}\left(B_{i m}^{*}\right)>(1+\varepsilon)\right\}<\infty .
$$

But the proof of this is essentially the same as given in $\S 4$ of Chover (1967). The only complication here is that the $m^{2}$ random variables $\left\{H_{\left[c^{n}\right]}\left(B_{i m}^{*}\right): 1 \leqq i \leqq m^{2}\right\}$ are not independent. But there is enough separation among these and it suffices to apply Lemma 1.1.5 in Iosifescu and Theodorescu (1969).

To prove (b) take $x \in K$ with $\int_{0}^{1} \int_{0}^{1}\left(\partial^{2} x / \partial t_{1} \partial t_{2}\right)^{2} d t_{1} d t_{2}<1$. We need to show that $\forall \varepsilon>0, P\left(\lim \inf d\left(H_{n}, x\right)<\varepsilon\right)=1$. Again in view of the preceding lemmas and the arguments in Sec.5 of Chover (1967) it is enough to prove for sufficiently small $\delta>0, \gamma>0$

$P\left(\lim _{n \rightarrow \infty} \sup F_{n}\right)=1$ where

$$
F_{n}=\left\{\left|H_{\left[c^{n}\right]}\left(B_{i m}^{*}\right)-x\left(B_{i m}\right)\right|<\delta, \text { all } i, \quad 1 \leqq i \leqq m^{2}\right\} .
$$

[It might be noted here that (35) in [2] is insufficient; it should be strengthened to $P\left(\lim _{r \rightarrow \infty} \sup \bigcap_{\nu} C_{r}^{(\nu)}\right)=1$.] Now if the probability of $F_{n}$ in computed on the assumption that the $m^{2}$ random variables $\left\{H_{\left[c^{n]}\right]}\left(B_{i m}^{*}\right): 1 \leqq i \leqq m^{2}\right\}$ are independent then the error committed is 
at most $m^{2} \phi_{\left[\nu c^{n}\right]}$ which forms a term of a convergent series in $n$. Hence using part (a) of the lemma on page 142 of [5] it is enough to show $\sum_{n} P\left(F_{n}\right)=\infty$. But given Theorem 1 this follows from computations which are standard in the proof of Strassen's theorem. This completes the proof of Theorem 2 .

ACKNOWLEDGMENT. We wish to thank the referee for bringing to our attention a recent and as yet unpublished paper "Strong Invariance Principles for Mixing Random Fields" by I. Berkes and G. Morrow. In this paper the authors prove a strong invariance principle for some dependent random fields. It should be pointed out however that our results do not follow from this strong invariance principle of Berkes and Morrow because, for $q>1$, the mixing condition we use is not comparable to the mixing condition employed by them.

\section{REFERENCES}

1. P. Billingsley, Convergence of Probability Measures, Wiley, New York, 1968.

2. J. Chover, On Strassen's version of the log log law, Z. Wahrscheinlichkeitstheorie verw. Geb., 8 (1967), 83-90.

3. C. M. Deo, A functional central limit theorem for stationary random fields, Ann. Probability, 4 (1975), 708-715.

4. — A note on $\phi$-mixing random fields, Theoria Verojatnoski i ee Primen., 21 (1976), 888-892.

5. - Delayed averages of mixing sequences, Canadian J. Statistics, 5 (1977), $141-145$.

6. M. Iosifescu and R. Theodorescu, Random Processes and Learning, Springer Verlag, New York, 1969.

7. W. Stout, Almost Sure Convergence, Academic Press, New York, 1974.

8. M. J. Wichura, Some Strassen-type laws of the iterated logarithm for multiparameter stochastic processes with independent increments, Ann. Probability, 2 (1973), 272-296.

Received October 5, 1977.

UNIVERSiTy OF OtTAWA

Ottawa Ontario, Canada K1N 6N5 



\section{PACIFIC JOURNAL OF MATHEMATICS}

\section{EDITORS}

DONALD BABBITT (Managing Editor)

University of California

Los Angeles, CA 90024

Hugo RossI

University of Utah

Salt Lake City, UT 84112

C. C. MOORE and ANDREW OGG

University of California

Berkeley, CA 94720

\section{J. DugundjI}

Department of Mathematics

University of Southern California

Los Angeles, CA 90007

R. FinN and J. Milgram

Stanford University

Stanford, CA 94305

\section{ASSOCIATE EDITORS}
E. F. BeCKENBACH
B. H. Neumann
F. WoLF
K. YoSHIDA

\section{SUPPORTING INSTITUTIONS}

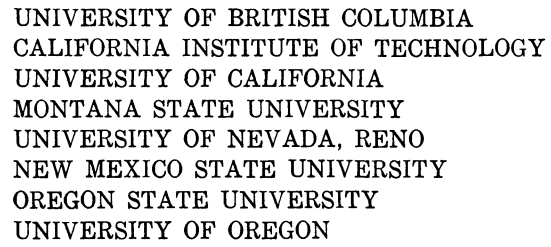

UNIVERSITY OF BRITISH COLUMBIA CALIFORNIA INSTITUTE OF TECHNOLOGY UNIVERSITY OF CALIFORNIA MONTANA STATE UNIVERSITY UNIVERSITY OF NEVADA, RENO NEW MEXICO STATE UNIVERSITY OREGON STATE UNIVERSITY UNIVERSITY OF OREGON

\author{
UNIVERSITY OF SOUTHERN CALIFORNIA \\ STANFORD UNIVERSITY \\ UNIVERSITY OF HAWAII \\ UNIVERSITY OF TOKYO \\ UNIVERSITY OF UTAH \\ WASHINGTON STATE UNIVERSITY \\ UNIVERSITY OF WASHINGTON
}

The Supporting Institutions listed above contribute to the cost of publication of this Journal, but they are not owners or publishers and have no responsibility for its content or policies.

Mathematical papers intended for publication in the Pacific Journal of Mathematics should be in typed form or offset-reproduced, (not dittoed), double spaced with large margins. Please do not use built up fractions in the text of the manuscript. However, you may use them in the displayed equations. Underline Greek letters in red, German in green, and script in blue. The first paragraph or two must be capable of being used separately as a synopsis of the entire paper. Please propose a heading for the odd numbered pages of less than 35 characters. Manuscripts, in triplicate, may be sent to any one of the editors. Please classify according to the scheme of Math. Reviews, Index to Vol. 39. Supply name and address of author to whom proofs should be sent. All other communications should be addressed to the managing editor, or Elaine Barth, University of California, Los Angeles, California, 90024.

50 reprints to each author are provided free for each article, only if page charges have been substantially paid. Additional copies may be obtained at cost in multiples of 50 .

The Pacific Journal of Mathematics is issued monthly as of January 1966. Regular subscription rate: $\$ 84.00$ a year (6 Vols., 12 issues). Special rate: $\$ 42.00$ a year to individual members of supporting institutions.

Subscriptions, orders for numbers issued in the last three calendar years, and changes of address shoud be sent to Pacific Journal of Mathematics, P.O. Box 969, Carmel Valley, CA 93924, U.S.A Old back numbers obtainable from Kraus Periodicals Co., Route 100, Millwood, NY 10546.

PUBLISHED BY PACIFIC JOURNAL OF MATHEMATICS, A NON-PROFIT CORPORATION

Printed at Kokusai Bunken Insatsusha (International Academic Printing Co., Ltd.). 8-8, 3-chome, Takadanobaba, Shinjuku-ku, Tokyo 160, Japan. 


\section{Pacific Journal of Mathematics}

\section{Vol. 91, No. 2 December, 1980}

Victor P. Camillo and Julius Martin Zelmanowitz, Dimension modules ... . . 249

Yonina S. Cooper, Stable sequences in pre-abelian categories ........... 263

Chandrakant Mahadeorao Deo and H. Ship-Fah Wong, On Berry-Esseen approximation and a functional LIL for a class of dependent random fields.........................................

H. P. Dikshit and S. N. Dubey, $|C, 1|$ summability of series associated with

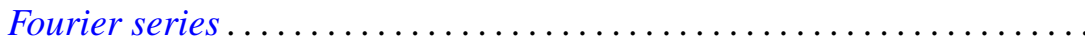

M. Edelstein, On the homomorphic and isomorphic embeddings of a semiflow into a radial flow.

Gilles Godefroy, Compacts de Rosenthal ..................... 293

James Guyker, Commuting hyponormal operators ................ 307

Thomas Eric Hall and Peter R. Jones, On the lattice of varieties of bands of

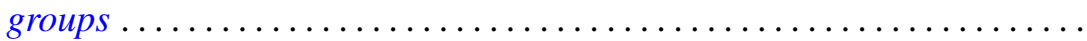

Taqdir Husain and Saleem H. Watson, Topological algebras with orthogonal Schauder bases ....................................

V. K. Jain, Some expansions involving basic hypergeometric functions of two variables. . .

Joe W. Jenkins, On group actions with nonzero fixed points ........... 363

Michael Ellsworth Mays, Groups of square-free order are scarce ........ 373

Michael John McAsey, Canonical models for invariant subspaces... 377

Peter A. McCoy, Singularities of solutions to linear second order elliptic partial differential equations with analytic coefficients by approximation methods...

Terrence Millar, Homogeneous models and decidability.

Stephen Carl Milne, A multiple series transformation of the very well poised

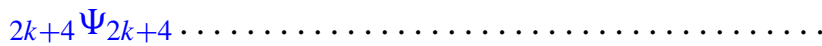

Robert Olin and James E. Thomson, Irreducible operators whose spectra are spectral sets...

Robert John Piacenza, Cohomology of diagrams and equivariant singular

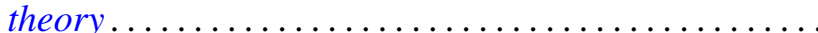

Louis Jackson Ratliff, Jr., Integrally closed ideals and asymptotic prime divisors

Robert Breckenridge Warfield, Jr., Cancellation of modules and groups and stable range of endomorphism rings.................

B. J. Day, Correction to: "Locale geometry" ...............

Stanley Stephen Page, Correction to: "Regular FPF rings" ... 